\title{
Molecular Rotation Spectrum of Tetracyclic Quinolizidines: Observation of trans-Matrine and the Elusive cis-Matrine
}

\author{
Marcos Juanes, ${ }^{\dagger}$ Rizalina Tama Saragi, ${ }^{\dagger}$ Lourdes Enríquez, ${ }^{\dagger}$ Martín Jaraíz,, \\ Alberto Lesarri, ${ }^{\dagger *}$
}

†Departamento de Química Física y Química Inorgánica, Facultad de Ciencias - I.U. CINQUIMA, Universidad de Valladolid, Paseo de Belén, 7, 47011 Valladolid, Spain

Departamento de Electrónica, ETSIT, Universidad de Valladolid, Paseo de Belén, 11, 47011 Valladolid, Spain

Corresponding autor:

Alberto Lesarri, alberto.lesarri@uva.es, Phone: +34-983-185895 


\section{TABLE OF CONTENTS GRAPHIC}

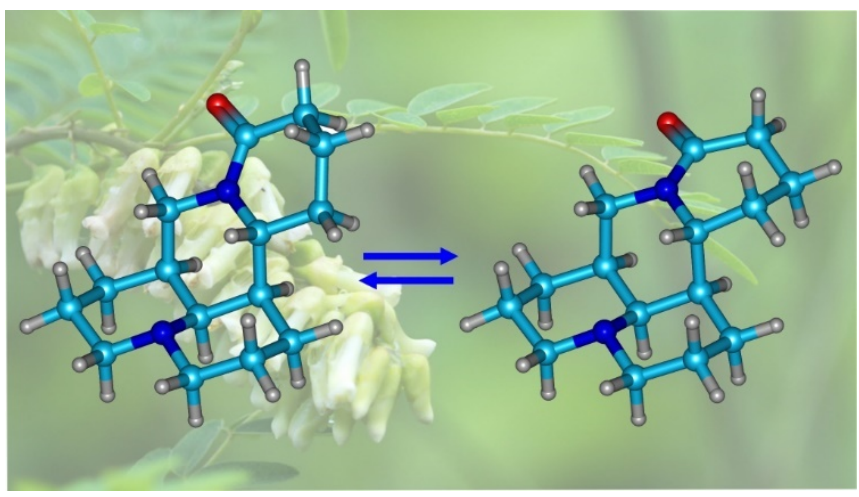

ABSTRACT: We characterized the bis-quinolizidine tetracyclic alkaloid (5S, 6S, 7R, 11R)-matrine in a supersonic jet expansion, using chirped-pulsed broadband microwave spectroscopy. Previous crystal diffraction analysis suggested 16 diastereoisomers associated to matrine's four carbon stereocenters, but were inconclusive whether the lactamic nitrogen atom would additionally produce separated trans-/cis-diastereoisomers or if both species may interconvert through low potential barriers. Our experiment simultaneously detected trans- and cis-matrine through their rotational spectrum, confirming the possibility of conformational rearrangement in matrine alkaloids. The two matrine conformers mainly differ in the envelope or half-chair lactamic ring, as evidenced by the experimental rotational and nuclear quadrupole coupling parameters. Molecular orbital calculations with ab initio (MP2) and density functional methods (B3LYP-D3(BJ) and MN15) were tested against the experiment, additionally offering an estimation of the cis-/trans- barrier of 24.9-26.9 $\mathrm{kJ} \mathrm{mol}^{-1}$. The experiment illustrates the structural potential of chirped-pulsed broadband microwave spectroscopy for high-resolution rotational studies of biomolecules in the range of 20-40 atoms. 


\section{INTRODUCTION}

Chirped-pulsed microwave spectroscopy is probably the last weapon to join the chemical arsenal of structural tools, following the introduction of broadband fast-passage excitation techniques by Pate, ${ }^{1-4}$ the discovery of rotational chiral detection ${ }^{5,6}$ and the recent availability of commercial equipment. This combination of factors has totally changed the face of molecular rotational resonance, but these advantages are still unnoticed for most practicing chemists. We illustrate the structural potential of broadband rotational spectroscopy for moderately-sized (ca. 20-40 atoms) molecules, seldom investigated in the gas phase and offering new avenues for pharmaceutical and chemical analysis ${ }^{7}$ and quantification of crude reaction mixtures. ${ }^{8}$

We report a first rotational study on the family of matrine alkaloids, never before examined in the gas phase. Matrine compounds belong to the class of quinolizidine alkaloids $^{9-12}$ and are broadly encountered in nature, especially in plants of the genera Sophora and Leontice. Matrine exhibits multiple pharmacological effects, as well as $\kappa-$ opiod and $\mu$-opiod receptor agonism. ${ }^{13}$ In particular, matrine displays strong antitumor activities, ${ }^{14}$ both in vitro and in vivo, and is an active component of the traditional Chinese medicine extracted from Sophora flavescens. ${ }^{15}$ Additionally, matrine has also shown acaricidal and insecticidal activity, ${ }^{16}$ so it may be used as bio-pesticide. The biological properties and biosynthesis are reviewed elsewhere. ${ }^{9-11}$

From a structural point of view matrine $\left(\mathrm{C}_{15} \mathrm{H}_{24} \mathrm{~N}_{2} \mathrm{O}\right)$ possesses a unique bisquinolizidine tetracyclic structure characterized by two asymmetrically condensed quinolizidine fragments, including (A/B) quinolizidinic and (C/D) quinilizidone ring systems. The molecule has four stereogenic carbon centers (C5, C6, C7 and C11 in Figure 1), which generate $2^{4}=16$ stereoisomers in 8 enantiomeric pairs. Half of these species have non-inverting equatorial trans-fused A/B rings, including (5S,6S,7R,11R)-matrine, 
Figure 1. Matrine alkaloids (diastereoisomers with A/B transand $\mathrm{A} / \mathrm{B}$ cis-fusion configurations are shown in the first and second row, respectively).
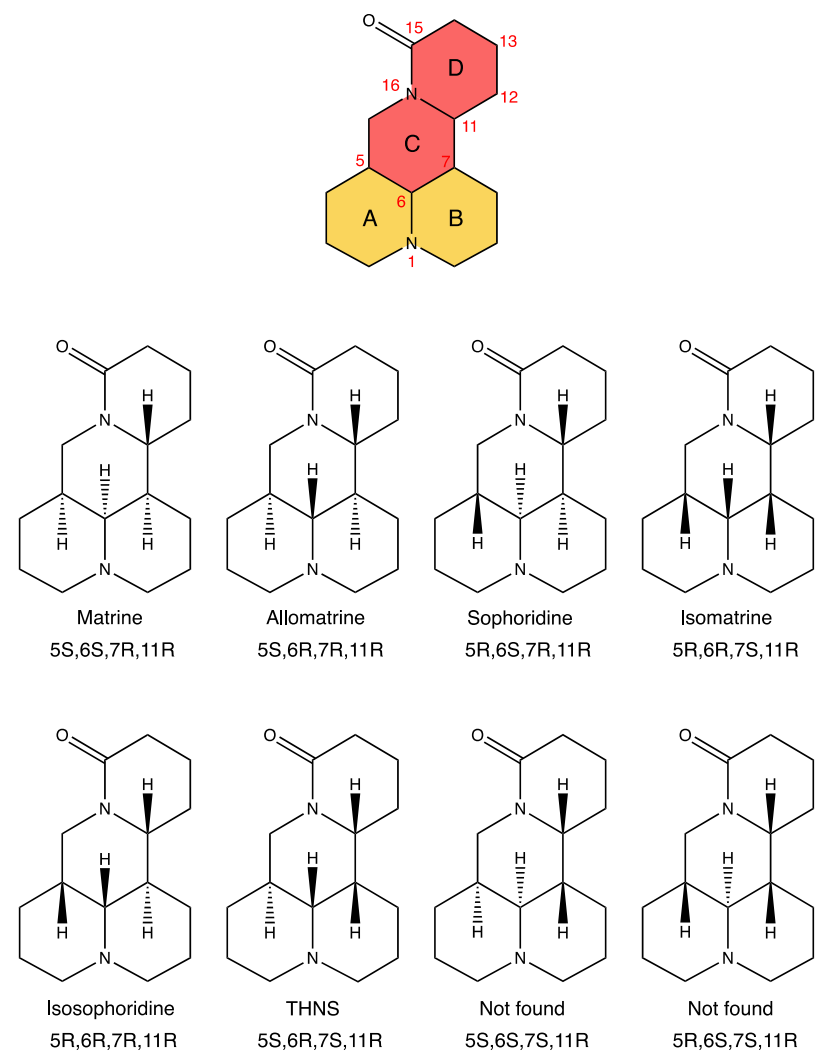

(5R,6S,7R,11R)-sophoridine, $\quad(5 \mathrm{R}, 6 \mathrm{R}, 7 \mathrm{~S}, 11 \mathrm{R})$-isomatrine $\quad$ and $\quad(5 \mathrm{~S}, 6 \mathrm{R}, 7 \mathrm{R}, 11 \mathrm{R})-$ allomatrine. Of the four $\mathrm{A} / \mathrm{B}$ cis-fused species only two species have been identified in nature $\quad((5 \mathrm{R}, 6 \mathrm{R}, 7 \mathrm{R}, 11 \mathrm{R})$-isosophoridine $\quad$ and $\quad(5 \mathrm{~S}, 6 \mathrm{R}, 7 \mathrm{~S}, 11 \mathrm{R})$-tetrahydroneosophoramine). Despite these molecules are apparently rigid, the different conformations for each ring (chair, boat, half-chair, etc), the alternative trans/cis-fusions for the $\mathrm{A} / \mathrm{B}, \mathrm{A}$ $\mathrm{B} / \mathrm{C}$ or $\mathrm{C} / \mathrm{D}$ ring junctions, the plausible nitrogen stereochemistry and the structural distortions associated to the ring fusion offer conformational variability. As a result, some confusion has remained in the literature concerning the stereochemical identification of 
matrine compounds, now mostly solved thanks to the combination of X-ray diffraction data $^{17-19}$ and IR, NMR and vibrational circular dichroism (VCD) experiments. ${ }^{20,21}$ However, some specific issues and the absolute configuration of several derivatives are still debatable. Concerning matrine stereochemistry, reviews by Ibragimov et al. ${ }^{22}$ based on the independent crystal diffraction observation of two different species denoted (C/D) trans-matrine ${ }^{23}$ and cis-matrine ${ }^{24}$ suggested that the two nitrogen atoms (N1 and N16) would behave as stereogenic centers, raising the number of different natural stereoisomers to $2^{6}=64$ or 32 enantiomeric pairs. This point of view was recently rebutted by Tashkhodzhaev and Vinogradova, ${ }^{25}$ who claimed that "cis-matrine is a non-existent quasi-diastereoisomer" and that distinguishing matrine molecules according to C/D ringfusion conformations is not correct. A previous IR and VCD study of matrine could not resolve this issue because of its low resolution $\left(4 \mathrm{~cm}^{-1}\right)$, justifying that those spectra "are essentially the same as those obtained with just the most stable trans-matrine", ${ }^{20}$

We now address this problem by observation of the molecular rotation of matrine in the gas phase, free of matrix, solvent or crystal effects. The high resolution $\left(10^{-7} \mathrm{~cm}^{-1}\right)$ of rotational spectra is critically sensitive to molecular structure, precisely resolving all populated species and offering the most accurate description of the intrinsic structural properties and plausible conformational equilibria in matrine. Our work follows previous rotational investigations of other quinolizidine alkaloids like sparteine ${ }^{26}$ and lupinine, ${ }^{27}$ and tropane ${ }^{28,29}$ and norbornane $\mathrm{e}^{30}$ bicycles and related derivatives. $^{31}$

\section{RESULTS AND DISCUSSION}

The spectral analysis was supported by ab initio and density functional theory molecular orbital calculations using the MP2, ${ }^{32}$ B3LYP-D3(BJ) ${ }^{33-35}$ and $\mathrm{MN} 15^{36}$ methods and a triple- $\zeta\left(\right.$ def2-TZVP $\left.{ }^{37}\right)$ basis set, described in the Methods section. The conformational 
search produced only the two low-lying isomers shown in Figure 2, differing in the C/D ring connection. Both species essentially correspond to the trans- and cis-matrine structures detected in the X-ray diffraction experiments (see 3D Figures S1-S2, structural parameters in Figures S3-S4 and atomic coordinates in Tables S1-S2, Supporting Information). Trans-matrine was predicted as global minimum, as in previous calculations, ${ }^{20,21}$ with cis-matrine at relative free energies of $2.0-2.6 \mathrm{~kJ} \mathrm{~mol}^{-1}$ at room temperature. This energy separation would ensure sufficient population for the gas-phase

Figure 2. Structural predictions for trans- and cis-matrine, showing the HOMO and representative dihedrals of the lactamic group (B3LYP-D3(BJ)/def2-TZVP, see 3D Figures S1-S2 and Tables S1-S3, SI).

trans-
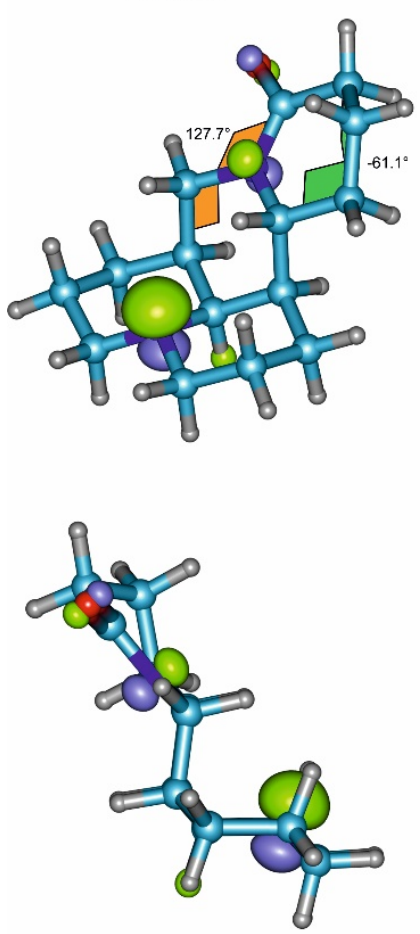

cis-
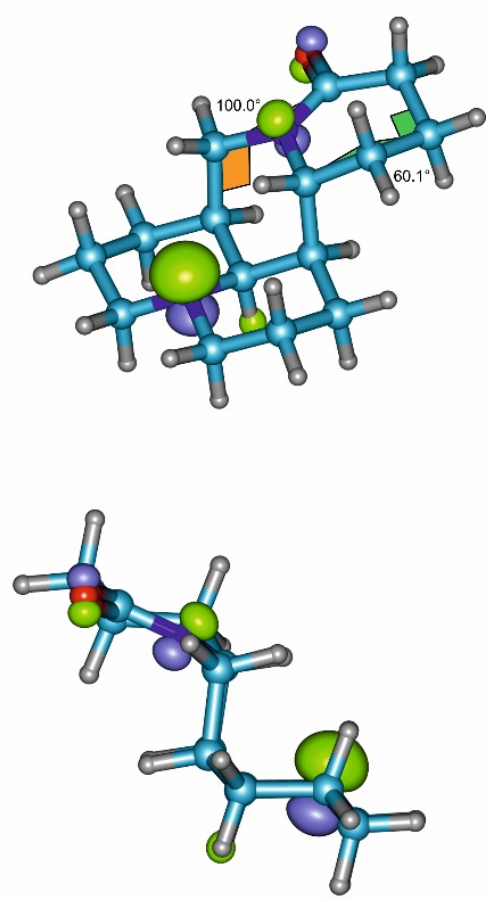
observation of the higher-energy isomer, provided that no low-barrier $\left(<5-10 \mathrm{~kJ} \mathrm{~mol}^{-1}\right)$ exist which might produce a conformational relaxation in the jet to the global minimum. ${ }^{38}$ We estimated the cis-/trans- interconversion barrier with B3LYP-D3(BJ) and MN15 using the intrinsic reaction coordinate (IRC) method, which corresponds to the minimum energy reaction pathway in mass-weighted cartesian coordinates between the transition state and reactants and products. The calculated Gibbs free-energy barriers of 24.9 and $26.9 \mathrm{~kJ} \mathrm{~mol}^{-1}$ in Figures 3 and S5 (SI) suggest that collisional mechanisms would be ineffective for conformational relaxation in the jet and that the two isomers may be observable in the spectrum. The predicted energetic and rotational parameters are presented in Table 1.

Figure 3. The interconversion barrier between cis- and transmatrine according to B3LYP-D3(BJ) (see Figure S5 for the MN15 calculation).

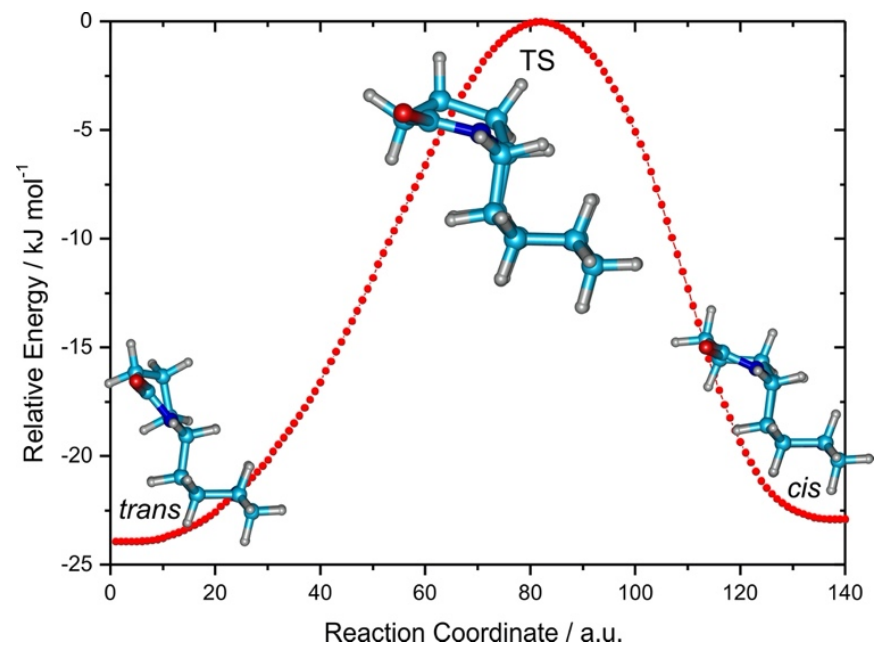

The computational predictions were checked against the experiment using a supersonic jet expansion of commercial matrine. The rotational spectrum was recorded 
using a broadband cm-wave chirped-pulsed microwave spectrometer (see Methods section). The spectrum was dense and complicated by multiple transitions showing small (0.5-2 MHz) hyperfine effects, as expected from the electric interaction between the nuclear quadrupoles of the two ${ }^{14} \mathrm{~N}(I=1)$ atoms of matrine and the molecular electric field gradient. This interaction couples the angular momenta of the nuclear spins $\left(\boldsymbol{I}_{1}, \boldsymbol{I}_{2}\right)$ to the overall molecular rotation $(\boldsymbol{J})$ according to Foley's coupling scheme ${ }^{39} \boldsymbol{I}=\boldsymbol{I}_{1}+\boldsymbol{I}_{2}, \boldsymbol{F}=$ $\boldsymbol{I}+\boldsymbol{J}$. A section of the spectrum and a typical transition are illustrated in Figure 4. Using trial rotational constants from the computational predictions the spectrum was searched iteratively for plausible spectral patterns. Finally, two different asymmetric rotors (I and II) were detected in the spectrum. More than 500 R-branch $(J+1 \leftarrow J) \mu_{\mathrm{a}^{-}}$and $\mu_{\mathrm{b}}$-type rotational transitions were measured for isomer I, which was fitted to a semirigid-rotor Watson's Hamiltonian with first-order (diagonal) nuclear quadrupole coupling terms. ${ }^{40}$ For isomer II a set of more than 200 transitions was measured and analyzed using the same Hamiltonian. The fitted experimental parameters are collected in Table 2 (rotational transitions in Tables S3-S4, SI). For both isomers the rotational and quadrupole coupling parameters were accurately determined, but the contribution of the centrifugal distortion was small and not all quartic parameters were determinable. The jet populations of the two isomers of matrine were later estimated from measurements of relative intensities assuming a quadratic dependence with the dipole moments and a uniform instrumental response. $^{2}$ We used a set of 10 rotational transitions and the (B3LYP-D3(BJ)) predicted electric dipole moments in Table 1, quite close for both isomers. This calculation gave conformational populations of $\mathrm{I}: \mathrm{II}=1: 0.29(7)$. On the assumption that the cis-/transbarrier makes the conformational population transfer negligible, a Boltzmann distribution gives an estimation for the potential energy difference between the two isomers of 3.0(6) $\mathrm{kJ} \mathrm{mol}^{-1}$ energy, which is consistent with the theoretical predictions. 
Figure 4. A $3 \mathrm{GHz}$ section of the microwave spectrum of matrine. The lower trace is a horizontal expansion illustrating the nuclear quadrupole coupling hyperfine effects in one of the rotational transitions of the transisomer (quantum numbers: $J, K_{-1}, K_{-1}, I, F$ ).
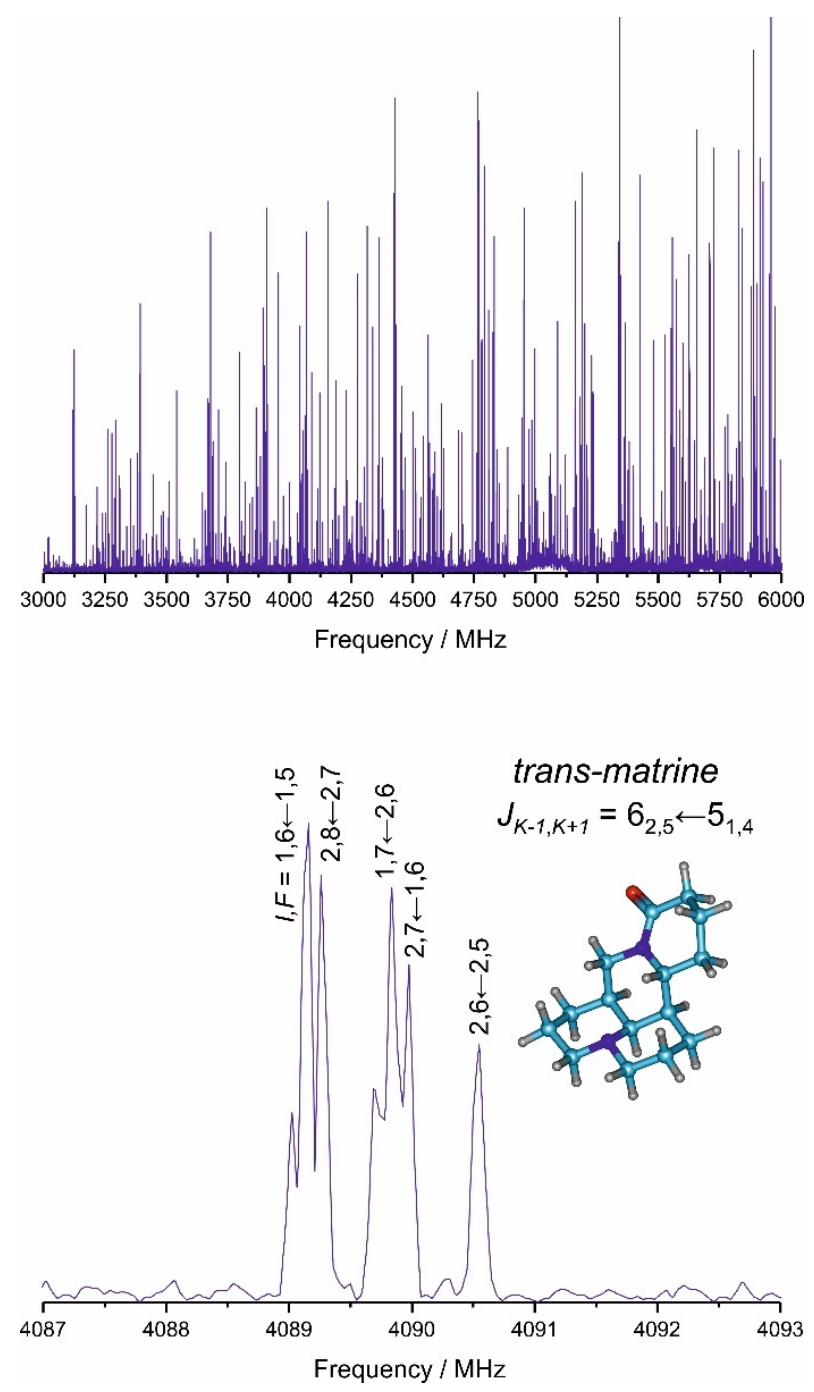

A comparison between experiment and computations in Tables 1-2 established the carriers of the spectrum. Following the good agreement of rotational constants and nuclear quadrupole coupling constants the most populated isomer I is unequivocally identified as trans-matrine, with isomer II corresponding to cis-matrine. The best agreement between experiment and theory was obtained for B3LYP-D3(BJ), with relative 
differences in the rotational constants of $0.1-0.5 \%\left(=\left(B_{\text {theo }}-B_{\text {exp }}\right) / B_{\text {exp }}\right)$. MP2 offered worse predictions $(0.8-2.1 \%)$ while MN15 was giving the poorest prediction $(1.2-2.7 \%)$. The agreement with the nuclear quadrupole coupling predictions was reasonable. These considerations assume that the vibrational corrections to the computational equilibrium structures are small ${ }^{41}(<1 \%)$ and do not impede valid conformational comparisons with the experimental ground-state parameters.

Table 1. Computational predictions for the isomers of matrine.

\begin{tabular}{|c|c|c|c|c|c|c|}
\hline & \multicolumn{2}{|c|}{ B3LYP-D3(BJ) ${ }^{\mathrm{f}}$} & \multicolumn{2}{|c|}{$\mathrm{MN} 15^{\mathrm{f}}$} & \multicolumn{2}{|c|}{$M P 2^{f}$} \\
\hline & trans- & cis- & trans- & cis- & trans- & cis- \\
\hline$A_{e} / \mathrm{MHz}^{\mathrm{a}}$ & 670.9 & 675.6 & 676.0 & 681.2 & 674.6 & 679.0 \\
\hline$B_{e} / \mathrm{MHz}$ & 373.9 & 391.8 & 380.8 & 404.1 & 379.4 & 401.7 \\
\hline$C_{e} / \mathrm{MHz}$ & 263.5 & 271.5 & 268.4 & 279.6 & 267.1 & 277.8 \\
\hline $3 / 2 \chi a a\left({ }^{14} \mathrm{~N}-1\right) / \mathrm{MHz}^{\mathrm{b}}$ & -0.10 & 1.67 & -0.23 & 1.79 & -0.02 & 1.75 \\
\hline $1 / 4\left(\chi_{\mathrm{bb}}-\chi_{c c}\right)\left({ }^{14} \mathrm{~N}-1\right) / \mathrm{MHz}$ & 1.32 & 1.62 & 1.29 & 1.64 & 1.16 & 1.47 \\
\hline $3 / 2 \chi_{a a}\left({ }^{14} \mathrm{~N}-16\right) / \mathrm{MHz}$ & 2.95 & 2.60 & 3.01 & 2.48 & 2.58 & 2.19 \\
\hline $1 / 4\left(\chi_{b b}-\chi_{c c}\right)\left({ }^{14} \mathrm{~N}-16\right) / \mathrm{MHz}$ & 1.67 & 1.58 & 1.66 & 1.54 & 1.51 & 1.41 \\
\hline$D_{J} / \mathrm{kHz}^{\mathrm{c}}$ & 0.0031 & 0.0080 & 0.0031 & 0.0105 & 0.0032 & 0.0092 \\
\hline$D_{J K} / \mathrm{kHz}$ & -0.0003 & -0.0089 & -0.0001 & -0.0118 & 0.0008 & -0.0104 \\
\hline$D_{K} / \mathrm{kHz}$ & 0.0086 & 0.0036 & 0.0079 & 0.0053 & 0.0079 & 0.0045 \\
\hline$d_{1} / \mathrm{kHz}$ & -0.0008 & 0.0004 & -0.0008 & 0.0010 & -0.0008 & 0.0007 \\
\hline$d_{2} / \mathrm{kHz}$ & -0.0001 & 0.0002 & -0.0001 & 0.0007 & -0.0001 & 0.0005 \\
\hline$\left|\mu_{\mathrm{a}}\right| / \mathrm{D}^{\mathrm{d}}$ & 2.45 & 2.31 & 2.42 & 2.10 & 2.4 & 2.0 \\
\hline$\left|\mu_{\mathrm{b}}\right| / \mathrm{D}$ & 3.68 & 3.62 & 3.66 & 3.58 & 3.7 & 3.6 \\
\hline$\left|\mu_{\mathrm{c}}\right| / \mathrm{D}$ & 0.09 & 0.14 & 0.01 & 0.33 & 0.1 & 0.1 \\
\hline$\Delta E_{Z P E} / \mathrm{kJ} \mathrm{mol}^{-1} \mathrm{e}$ & 0.00 & 1.85 & 0.00 & 1.73 & 0.00 & 0.82 \\
\hline$\Delta G / \mathrm{kJ} \mathrm{mol}^{-1}$ & 0.00 & 2.62 & 0.00 & 2.17 & 0.00 & 1.95 \\
\hline
\end{tabular}


Table 2. Experimental rotational parameters of the trans- and cisisomers of matrine.

\begin{tabular}{|c|c|c|}
\hline & \multicolumn{2}{|c|}{ Experiment } \\
\hline & trans-Matrine & cis-Matrine \\
\hline$A_{0} / \mathrm{MHz}^{\mathrm{a}}$ & $667.96909(47)$ & $673.3856(22)$ \\
\hline$B_{0} / \mathrm{MHz}$ & $373.52761(25)$ & $393.57019(66)$ \\
\hline$C_{0} / \mathrm{MHz}$ & $263.40264(24)$ & $272.65497(44)$ \\
\hline $3 / 2 \chi_{a a}\left({ }^{14} \mathrm{~N}-1\right) / \mathrm{MHz}^{\mathrm{b}}$ & $-0.293(97)$ & $1.29(14)$ \\
\hline $1 / 4\left(\chi_{b b}-\chi_{c c}\right)\left({ }^{14} \mathrm{~N}-1\right) / \mathrm{MHz}$ & $1.164(20)$ & $1.435(44)$ \\
\hline $3 / 2 \chi_{a a}\left({ }^{14} \mathrm{~N}-16\right) / \mathrm{MHz}$ & $2.883(84)$ & $2.59(14)$ \\
\hline $1 / 4\left(\chi_{b b}-\chi_{c c}\right)\left({ }^{14} \mathrm{~N}-16\right) / \mathrm{MHz}$ & $1.609(20)$ & $1.560(46)$ \\
\hline$D_{J} / \mathrm{kHz}^{\mathrm{c}}$ & $-0.00135(94)$ & {$[0.0]$} \\
\hline$D_{J K} / \mathrm{kHz}$ & {$[0.0]$} & $0.083(42)$ \\
\hline$D_{K} / \mathrm{kHz}$ & {$[0.0]$} & $-3.62(15)$ \\
\hline$N^{\mathrm{d}}$ & 508 & 228 \\
\hline$\sigma / \mathrm{kHz}$ & 21.2 & 38.2 \\
\hline
\end{tabular}

Trans- and cis-matrine share a common A/B/C ring system, based on three $\left({ }^{2} \mathrm{C}_{5}\right.$, ${ }^{10} \mathrm{C}_{7},{ }^{6} \mathrm{C}_{16}$ ) chairs with trans- ring junctions for $\mathrm{A} / \mathrm{B}$ and cis- unions for $\mathrm{A} / \mathrm{C}$ and $\mathrm{B} / \mathrm{C}$ (conformational descriptors follow ref. 42). The D lactamic ring is characterized by the partial double bond character of the $\mathrm{C}-\mathrm{N}$ bond but may show differences in the planarity of the amide group and orientation of $\mathrm{C} 12$ and $\mathrm{C} 13$, leading to near-envelope (E) or halfchair $(\mathrm{H})$ conformations. The $\mathrm{C} / \mathrm{D}$ trans- union represents the global minimum and exhibits a near-planar amidic nitrogen (sum of internal angles of $359.6^{\circ}$ ), which should be referred more properly as transoid..$^{21}$ Because of the planarity of the lactamic fragment $\mathrm{C} 14-\mathrm{C} 15-\mathrm{N} 16-\mathrm{C} 11\left(\tau=-0.5^{\circ}\right), \mathrm{C} 13$ moves away from the average ring plane, giving a distorted ${ }^{13}$ E envelope. Figure S6 and Table S5 collect the Cremer-Pople ring puckering coordinates $^{43}\left(q_{2}, q_{3}, \phi, \theta\right)$ for the lactamic ring, which locate the global minimum D-ring conformation $\left(\theta=128.7^{\circ}, \phi=11.8^{\circ}\right)$ on the negative $\left(q_{3}<0\right)$ envelope/half-chair pseudorotation pathway $\left(\theta=125.5^{\circ}-129.2\right)$ of the conformational globe. ${ }^{44}$ Conversely, the cis- or cisoid isomer has indications of a larger conformational strain, showing a small $\mathrm{N}$ 
pyramidalization (sum of internal angles of $357.0^{\circ}$ ) and deviation of the lactamic fragment C14-C15-N16-C11 from linearity $\left(\tau=-16.5^{\circ}\right)$, which results in a ${ }^{12} \mathrm{H}_{13}$ half-chair isomer (C12 and C13 on opposite sides of the average plane), with puckering coordinates $(\theta=37.2, \phi=217.2)$ close to the positive $\left(q_{3}>0\right)$ envelope/half-chair pseudorotation pathway $\left(\theta=50.8^{\circ}-54.7^{\circ}\right)$. The gas-phase structural data are qualitatively similar to the solid phase (i.e., differences in torsion angles of $1-5^{\circ}$ in Figure S3, SI) ${ }^{23,24}$ and confirm that the origin of matrine isomerism is intrinsic to the molecule and cannot be attributed to crystal packing effects or intermolecular forces. Because of the relatively small potential barriers, neither the lactamic conformational rearrangements nor the plausible amine inversion isomerism ${ }^{45}$ of matrine produce rigid stereocenters and cannot be referred as diastereoisomers. The proposed existence of 32 matrine enantiomeric pairs ${ }^{22}$ is thus incorrect, as suggested. ${ }^{25}$

\section{CONCLUSION}

We have observed two isomers of matrine in the gas phase, confirming the presence of conformational rearrangements in matrine alkaloids and its independence of any crystal packing effects in the solid. Matrine isomerism is attributed to the conformational strain of the lactamic six-membered ring of the tetracycle. Chirality cannot be associated with the near-planar conformation of the lactamic nitrogen bridgehead nor to the pyramidal amine because of its facile nitrogen inversion, previously observed in other alkaloids. ${ }^{45}$ While conformational changes were previously observed in the bis-quinolizidine ring system of sparteine, ${ }^{26}$ this is the first direct observation of isomerism in isolated tetracyclic matrine alkaloids. We anticipate that other isomers may be found for matrine diastereoisomers and derivatives where several conformers are predicted to lie close in energy, like sophoridine and oxymatrine. ${ }^{20}$ 
The value of the new broadband chirped-pulse microwave spectroscopy techniques for gas-phase stereochemical and structural characterization of moderatelysized biochemical molecules is finally emphasized. Rotational spectroscopy appears particularly useful for complex multiconformational biochemical systems, where conventional techniques in condensed phases like IR and VCD may show deficiencies for structural identification. In these cases, the broadband and high-resolution advantage of rotational spectroscopy may contribute significantly to the advance of the techniques of chemical analysis ${ }^{7,8}$ used in academia and industry.

\section{EXPERIMENTAL AND COMPUTATIONAL METHODS}

The experiment was conducted with a supersonic-jet chirped-pulsed Fourier-transform microwave (CP-FTMW) spectrometer at the University of Valladolid, covering the frequency region 2-8 GHz. The spectrometer uses a direct-digital design following Pate. ${ }^{1}$ In this technique a short (1-5 $\mu \mathrm{s})$ linear microwave chirp is synthesized digitally with an arbitrary-wave generator, exciting the rotational resonances of the expanding molecular jet. The chirp is amplified to $20 \mathrm{~W}$ and broadcasted into the jet through a horn antenna, perpendicular to the vertically moving jet. The jet originates from a pulsed solenoid valve (Parker, series 9), which injects a gaseous mixture into the expansion chamber through a $0.8 \mathrm{~mm}$-size circular nozzle. The gas expands into an ultimate vacuum pressure of ca. $10^{-7} \mathrm{hPa}$ at typical stagnation pressures of 1-3 bar. Matrine $(98 \%, \mathrm{GC})$ was obtained commercially (TCI Chemicals) and used without any further purification. The sample was vaporized at temperatures in the rage of $140-165^{\circ} \mathrm{C}$, using neon $(99.999 \%)$ as carrier gas. Gas pulses were typically of $900 \mu$ s duration. The effective rotational temperatures produced in the expansion were estimated as $2 \mathrm{~K}$. Following the transient excitation the spectrometer records the time-domain free-induction decay caused by rotational 
dephasing, using a receiver made of a horn antenna, low-noise amplifiers and a digital oscilloscope. Typical acquisition times are of $40 \mu \mathrm{s}$. Normally a single gas pulse is probed several times to increase the signal-to-noise level. The final time-domain record is Fourier transformed using a Kaiser-Bessel window, resulting in linewidths of ca. $100 \mathrm{kHz}$. Frequency uncertainties for the experimental measurements were estimated as $20 \mathrm{kHz}$ for the fits of Table 2. For the present purposes ca. $1 \mathrm{M}$ spectral averages were acquired at a repetition rate of $5 \mathrm{~Hz}$.

The computational methods included an initial conformational search with molecular mechanics, followed by molecular orbital calculations using ab initio and Kohn-Sham density-functional-theory. Molecular mechanics used the MMFFs force field ${ }^{46}$ and were implemented in Macromodel. ${ }^{47}$ Geometry optimizations and harmonic vibrational frequency calculations were carried out with the B3LYP, ${ }^{33} \mathrm{MN} 15^{36}$ and MP2 $2^{32}$ methods (absolute energies and lowest vibrational frequencies in Tables S6-S7, SI). The Becke's three-parameter functional was supplemented with two-body Grimme's D3(BJ) dispersion ${ }^{34}$ corrections with Becke-Johnson ${ }^{35}$ damping. All calculations were combined with the Alrich's balanced triple- $\zeta$ def2-TZVP basis set. ${ }^{37}$ DFT calculations were implemented in Gaussian $16 .{ }^{48}$ For the interconversion barrier the intermediates, products and transition states were located by means of the GRRM (Global Reaction Route Mapping) program, ${ }^{49}$ linked to Gaussian16. Transition state structures were optimized as saddle points at the same level of calculation. To verify that they correspond to the expected reactant and product wells, intrinsic reaction coordinate (IRC) calculations were performed at the same level. 


\section{ASSOCIATED CONTENT}

\section{Supporting Information}

The Supporting Information is available free of charge at ...

Additional figures with rotatable structures and molecular parameters

Tables of ab initio structural data

Observed frequencies of rotational transitions 


\section{AUTHOR INFORMATION}

\section{Corresponding author}

Alberto Lesarri - Departamento de Química Física y Química Inorgánica, Facultad de Ciencias - I.U. CINQUIMA, Universidad de Valladolid, Paseo de Belén, 7, 47011 Valladolid, Spain; ORCID: 0000-0002-0646-6341

\section{Authors}

Marcos Juanes - Departamento de Química Física y Química Inorgánica, Facultad de Ciencias - I.U. CINQUIMA, Universidad de Valladolid, Paseo de Belén, 7, 47011 Valladolid, Spain; ORCID: 0000-0002-7257-8632

Rizalina Tama Saragi - Departamento de Química Física y Química Inorgánica, Facultad de Ciencias - I.U. CINQUIMA, Universidad de Valladolid, Paseo de Belén, 7, 47011 Valladolid, Spain; ORCID: 0000-0003-4472-357X

Lourdes Enríquez - Departamento de Electrónica, ETSIT, Universidad de Valladolid, Paseo de Belén, 11, 47011 Valladolid, Spain; ORCID: 0000-00020655-7518

Martín Jaraíz - Departamento de Electrónica, ETSIT, Universidad de Valladolid, Paseo de Belén, 11, 47011 Valladolid, Spain; ORCID: 0000-0001-6688-3158

\section{Notes}

The authors declare no competing financial interest.

\section{ACKNOWLEDGEMENTS}

Funding support from the Spanish MICINN-FEDER (grant PGC2018-098561- B-C22) and JCyL (grant VA056G18) is gratefully acknowledged. M.J. and R.T.S. are thankful for predoctoral contracts from the MICINN and UVa, respectively. 


\section{REFERENCES}

(1) Shipman, S. T.; Pate, B. H. New Techniques in Microwave Spectroscopy. In Handbook of High-resolution Spectroscopy; Merkt, F., Quack, M., Eds.; Major Reference Works; John Wiley \& Sons, Ltd: New York, 2011; pp 801-828. https://doi.org/10.1002/9780470749593.hrs036.

(2) Grabow, J.-U. Fourier Transform Microwave Spectroscopy Measurement and Instrumentation. In Handbook of High-resolution Spectroscopy; Merkt, F., Quack, M., Eds.; John Wiley \& Sons, Ltd: New York, 2011; pp 723-799. https://doi.org/10.1002/9780470749593.hrs037.

(3) Caminati, W.; Grabow, J.-U. Advancements in Microwave Spectroscopy. In Frontiers and Advances in Molecular Spectroscopy; Laane, J., Ed.; Elsevier Inc., 2018; pp 569-598. https://doi.org/10.1016/B978-0-12-811220-5.00018-6.

(4) Park, G. B.; Field, R. W. Perspective: The First Ten Years of Broadband Chirped Pulse Fourier Transform Microwave Spectroscopy. J. Chem. Phys. 2016, 144 (20), 1-10. https://doi.org/10.1063/1.4952762.

(5) Pate, B. H.; Evangelisti, L.; Caminati, W.; Xu, Y.; Thomas, J.; Patterson, D.; Perez, C.; Schnell, M. Quantitative Chiral Analysis by Molecular Rotational Spectroscopy. In Chiral Analysis: Advances in Spectroscopy, Chromatography and Emerging Methods: Second Edition; Elsevier B.V., 2018; pp 679-729. https://doi.org/10.1016/B978-0-444-64027-7.00019-7.

(6) Domingos, S. R.; Pérez, C.; Marshall, M. D.; Leung, H. O.; Schnell, M. Assessing the Performance of Rotational Spectroscopy in Chiral Analysis. Chem. Sci. 2020, 10863-10870. https://doi.org/10.1039/d0sc03752d.

(7) Neill, J. L.; Mikhonin, A. V.; Chen, T.; Sonstrom, R. E.; Pate, B. H. Rapid Quantification of Isomeric and Dehalogenated Impurities in Pharmaceutical Raw Materials Using MRR Spectroscopy. J. Pharm. Biomed. Anal. 2020, 189, 113474. https://doi.org/10.1016/j.jpba.2020.113474.

(8) Joyce, L. A.; Schultz, D. M.; Sherer, E. C.; Neill, J. L.; Sonstrom, R. E.; Pate, B. H. Direct Regioisomer Analysis of Crude Reaction Mixtures: Via Molecular Rotational Resonance (MRR) Spectroscopy. Chem. Sci. 2020, 11 (24), 6332-6338. https://doi.org/10.1039/d0sc01853h.

(9) Aniszewski, T. Alkaloids, Chemistry, Biology, Ecology, and Applications, Second.; Elsevier Science: Amsterdam, 2015. https://doi.org/10.1016/C2011-004166-2.

(10) Bunsupa, S.; Yamazaki, M.; Saito, K. Quinolizidine Alkaloid Biosynthesis: Recent Advances and Future Prospects. Front. Plant Sci. 2012, 3 (OCT), 1-7. https://doi.org/10.3389/fpls.2012.00239.

(11) Robins, D. J. Chapter 1 Biosynthesis of Pyrrolizidine and Quinolizidine Alkaloids; 1995; pp 1-61. https://doi.org/10.1016/S0099-9598(08)60285-0.

(12) Shakirov, R.; Telezhenetskaya, M. V.; Bessonova, I. A.; Aripova, S. F.; Israilov, I. A.; Sultankhodzhaev, M. N.; Vinogradova, V. I.; Akhmedzhanova, V. I.; Tulyaganov, T. S.; Salimov, B. T.; Tel'nov, V. A. Alkaloids. Plants, Structures, Properties. Chem. Nat. Compd. 1996, 32 (4), 596-675. https://doi.org/10.1007/BF01372626.

(13) Xiao, P.; Kubo, H.; Ohsawa, M.; Higashiyama, K.; Nagase, H.; Yan, Y. N.; Li, J. S.; Kamei, J.; Ohmiya, S. Kappa-Opioid Receptor-Mediated Antinociceptive Effects of Stereoisomers and Derivatives of (+)-Matrine in Mice. Planta Med. 1999, 65 (3), 230-233. https://doi.org/10.1055/s-1999-14080.

(14) Ma, L.; Wen, S.; Zhan, Y.; He, Y.; Liu, X.; Jiang, J. Anticancer Effects of the Chinese Medicine Matrine on Murine Hepatocellular Carcinoma Cells. Planta 
Med. 2008, 74 (3), 245-251. https://doi.org/10.1055/s-2008-1034304.

(15) He, X.; Fang, J.; Huang, L.; Wang, J.; Huang, X. Sophora Flavescens Ait.: Traditional Usage, Phytochemistry and Pharmacology of an Important Traditional Chinese Medicine. J. Ethnopharmacol. 2015, 172, 10-29. https://doi.org/10.1016/j.jep.2015.06.010.

(16) Matsuda, K.; Yamada, K.; Kimura, M.; Hamada, M. Nematicidal Activity of Matrine and Its Derivatives against Pine Wood Nematodes. J. Agric. Food Chem. 1991, 39 (1), 189-191. https://doi.org/10.1021/jf00001a038.

(17) Tashkhodzhaev, B.; Vinogradova, V. I. Structures of Darvasine, Leontalbine, Albertamine, and Darvasamine. Chem. Nat. Compd. 2018, 54 (6), 1123-1126. https://doi.org/10.1007/s10600-018-2570-1.

(18) Jin, Z. M.; Ma, L. L.; Wei, W. X.; Li, Y. Q. On the Absolute Configuration of Matrine: Crystal Structure of Matrin-1-Ium-Trichlorozincate. J. Struct. Chem. 2009, 50 (1), 190-194. https://doi.org/10.1007/s10947-009-0028-9.

(19) Ibragimov, B. T.; Tishchenko, G. N.; Talipov, S. A.; Kushmuradov, Y. K.; Aripov, T. F. Structure of Isosophoridine. Chem. Nat. Compd. 1981, 17 (4), 340-344. https://doi.org/10.1007/BF01185262.

(20) Zhang, Y.; Poopari, M. R.; Cai, X.; Savin, A.; Dezhahang, Z.; Cheramy, J.; Xu, Y. IR and Vibrational Circular Dichroism Spectroscopy of Matrine- and ArtemisininType Herbal Products: Stereochemical Characterization and Solvent Effects. $J$. Nat. $\quad$ Prod. 2016, 79 (4), 1012-1023. https://doi.org/10.1021/acs.jnatprod.5b01082.

(21) Galasso, V.; Asaro, F.; Berti, F.; Pergolese, B.; Kovač, B.; Pichierri, F. On the Molecular and Electronic Structure of Matrine-Type Alkaloids. Chem. Phys. 2006, 330 (3), 457-468. https://doi.org/10.1016/j.chemphys.2006.09.017.

(22) Ibragimov, B. T.; Tishchenko, G. N.; Kushmuradov, Y. K.; Talipov, S. A.; Aripov, T. F. Stereoisomerism of the Matrine Alkaloids. Chem. Nat. Compd. 1982, 18 (1), 66-69. https://doi.org/10.1007/BF00581599.

(23) Ibragimov, B. T.; Talipov, S. A.; Tishchenko, G. N.; Kushmuradov, Y. K.; Aripov, T. F. Molecular and Crystal Structure of Matrine. Kristallografiya 1978, 23 (6), 1189-1195.

(24) Ibragimov, B. T.; Talipov, S. A.; Kushmuradov, Y. K.; Aripov, T. F. An X-Ray Structural Investigation of Cis-Matrine - A New Stereoisomer of Matrine. Chem. Nat. Compd. 1981, 17, 432-436. https://doi.org/10.1007/BF00565156.

(25) Tashkhodzhaev, B.; Vinogradova, V. I. On the Stereochemistry of Matrine-Type Alkaloids. Chem. Nat. Compd. 2018, 54 (6), 1127-1130. https://doi.org/10.1007/s10600-018-2571-0.

(26) Lesarri, A.; Pinacho, R.; Enríquez, L.; Rubio, J. E.; Jaraíz, M.; Abad, J. L.; Gigosos, M. A. Rotational Spectra of Tetracyclic Quinolizidine Alkaloids: Does a Water Molecule Flip Sparteine? Phys. Chem. Chem. Phys. 2017, 19 (27), 1755317559. https://doi.org/10.1039/c7cp01432e.

(27) Jahn, M. K.; Dewald, D.; Vallejo-López, M.; Cocinero, E. J.; Lesarri, A.; Grabow, J.-U. Rotational Spectra of Bicyclic Decanes: The Trans Conformation of (-)Lupinine. J. Phys. Chem. A 2013, 117 (50), 13673-13679. https://doi.org/10.1021/jp407671m.

(28) Vallejo-López, M.; Écija, P.; Vogt, N.; Demaison, J.; Lesarri, A.; Basterretxea, F. J.; Cocinero, E. J. N-Methyl Inversion and Accurate Equilibrium Structures in Alkaloids: Pseudopelletierine. Chem. - A Eur. J. 2017, 23 (65), 16491-16496. https://doi.org/10.1002/chem.201702232.

(29) Cocinero, E. J.; Lesarri, A.; Écija, P.; Grabow, J.-U.; Fernández, J. A.; Castaño, F. 
N-Methyl Stereochemistry in Tropinone: The Conformational Flexibility of the Tropane Motif. Phys. Chem. Chem. Phys. 2010, 12 (23), 6076-6083. https://doi.org/10.1039/c000528b.

(30) Écija, P.; Uriarte, I.; Basterretxea, F. J.; Millán, J.; Lesarri, A.; Fernández, J. A.; Cocinero, E. J. Structural Distortion of the Epoxy Groups in Norbornanes: A Rotational Study of Exo-2,3-Epoxynorbornane. ChemPhysChem 2015, 16 (12), 2609-2614. https://doi.org/10.1002/cphc.201500334.

(31) Wachsmuth, D.; Jahn, M. K.; Blanco, S.; Gigosos, M. A.; Lesarri, A.; Grabow, J.U. Inversion of Bicyclic Decanes: Rotational Spectra of the Trans and Double Cis Conformations of 2-Decalone. ChemPhysChem 2017, 18 (24), 3620-3624. https://doi.org/10.1002/cphc.201700848.

(32) Møller, C.; Plesset, M. S. Note on an Approximation Treatment for Many-Electron Systems. Phys. Rev. 1934, 46, 618-622.

(33) Becke, A. D. Density-Functional Thermochemistry. III. The Role of Exact Exchange. J. Chem. Phys. 1993, 98 (7), 5648-5652. https://doi.org/10.1063/1.464913.

(34) Grimme, S.; Antony, J.; Ehrlich, S.; Krieg, H. A Consistent and Accurate Ab Initio Parametrization of Density Functional Dispersion Correction (DFT-D) for the 94 Elements H-Pu. J. Chem. Phys. 2010, 132 (15), 1-19. https://doi.org/10.1063/1.3382344.

(35) Johnson, E. R.; Becke, A. D. A Post-Hartree-Fock Model of Intermolecular Interactions: Inclusion of Higher-Order Corrections. J. Chem. Phys. 2006, 124 (17), 174104. https://doi.org/10.1063/1.2190220.

(36) Yu, H. S.; He, X.; Li, S. L.; Truhlar, D. G. MN15: A Kohn-Sham Global-Hybrid Exchange-Correlation Density Functional with Broad Accuracy for MultiReference and Single-Reference Systems and Noncovalent Interactions. Chem. Sci. 2016, 7 (8), 5032-5051. https://doi.org/10.1039/C6SC00705H.

(37) Weigend, F.; Ahlrichs, R. Balanced Basis Sets of Split Valence, Triple Zeta Valence and Quadruple Zeta Valence Quality for H to Rn: Design and Assessment of Accuracy. Phys. Chem. Chem. Phys. 2005, 7 (18), 3297. https://doi.org/10.1039/b508541a.

(38) Godfrey, P. D.; Brown, R. D. Proportions of Species Observed in Jet Spectroscopy-Vibrational-Energy Effects: Histamine Tautomers and Conformers. J. Am. Chem. Soc. 1998, 120 (41), 10724-10732. https://doi.org/10.1021/ja980560m.

(39) Foley, H. M. Note on the Nuclear Electric Quadrupole Spectrum of a Homonuclear Diatomic Molecule in a Magnetic Field. Phys. Rev. 1947, 71 (11), 747-751. https://doi.org/10.1103/PhysRev.71.747.

(40) Gordy, W.; Cook, R. L. Microwave Molecular Spectra; John Wiley \& Sons, Inc: New York, NY, 1984.

(41) Grimme, S.; Steinmetz, M. Effects of London Dispersion Correction in Density Functional Theory on the Structures of Organic Molecules in the Gas Phase. Phys. Chem. Chem. Phys. 2013, 15 (38), 16031-16042. https://doi.org/10.1039/c3cp52293h.

(42) McNaught, A. D. Nomenclature of Carbohydrates (IUPAC Recommendations 1996). Pure Appl. Chem. 1996, 68 (10), 1919-2008. https://doi.org/10.1351/pac199668101919.

(43) Cremer, D.; Pople, J. A. General Definition of Ring Puckering Coordinates. J. Am. Chem. Soc. 1975, 97 (6), 1354-1358. https://doi.org/10.1021/ja00839a011.

(44) Cremer, D.; Szabo, K. J. Ab Initio Studies of Six-Membered Rings: Present Status 
and Future Developments. In Modern Conformational Analysis; Juaristi, E., Ed.; VCH: New York, NY, 1995; pp 59-135. https://doi.org/10.1002/chin.199541313.

(45) Adizov, S. M.; Tashkhodzhaev, B.; Bruskov, V. P.; Talipov, S. A.; Yuldashev, P. K.; Malikov, V. M. On Nitrogen Coordination in Vincadifformine-Type Alkaloids. Chem. Nat. Compd. 2017, 53 (3), 512-516. https://doi.org/10.1007/s10600-0172034-z.

(46) Halgren, T. A. Merck Molecular Force Field. II. MMFF94 van Der Waals and Electrostatic Parameters for Intermolecular Interactions. J. Comput. Chem. 1996, 17 (5-6), 520-552. https://doi.org/10.1002/(SICI)1096987X(199604)17:5/6<520::AID-JCC2>3.0.CO;2-W.

(47) MacroModel, Schrödinger Release 2020-1: Schrödinger, LLC: New York, NY 2020.

(48) Frisch, M. J.; Trucks, G. W.; Schlegel, H. B.; Scuseria, G. E.; Robb, M. A.; Cheeseman, J. R.; Scalmani, G.; Barone, V.; Petersson, G. A.; Nakatsuji, H.; Li, X.; Caricato, M.; Marenich, A. V.; Bloino, J.; Janesko, B. G.; Gomperts, R.; Mennucci, B.; Hratchian, H. P.; Ortiz, J. V.; Izmaylov, A. F.; Sonnenberg, J. L.; Williams; Ding, F.; Lipparini, F.; Egidi, F.; Goings, J.; Peng, B.; Petrone, A.; Henderson, T.; Ranasinghe, D.; Zakrzewski, V. G.; Gao, J.; Rega, N.; Zheng, G.; Liang, W.; Hada, M.; Ehara, M.; Toyota, K.; Fukuda, R.; Hasegawa, J.; Ishida, M.; Nakajima, T.; Honda, Y.; Kitao, O.; Nakai, H.; Vreven, T.; Throssell, K.; Montgomery Jr., J. A.; Peralta, J. E.; Ogliaro, F.; Bearpark, M. J.; Heyd, J. J.; Brothers, E. N.; Kudin, K. N.; Staroverov, V. N.; Keith, T. A.; Kobayashi, R.; Normand, J.; Raghavachari, K.; Rendell, A. P.; Burant, J. C.; Iyengar, S. S.; Tomasi, J.; Cossi, M.; Millam, J. M.; Klene, M.; Adamo, C.; Cammi, R.; Ochterski, J. W.; Martin, R. L.; Morokuma, K.; Farkas, O.; Foresman, J. B.; Fox, D. J. Gaussian 16, Rev. C.01. Gaussian, Inc: Wallingford CT 2016.

(49) Ohno, K.; Maeda, S. A Scaled Hypersphere Search Method for the Topography of Reaction Pathways on the Potential Energy Surface. Chem. Phys. Lett. 2004, 384 (4-6), 277-282. https://doi.org/10.1016/j.cplett.2003.12.030. 